\title{
Metabotyping: A New Approach to Investigate Rapeseed (Brassica napus L.) Genetic Diversity in the Metabolic Response to Clubroot Infection
}

\author{
Geoffrey Wagner, ${ }^{1,2}$ Sophie Charton, ${ }^{3}$ Christine Lariagon, ${ }^{3}$ Anne Laperche,,${ }^{1,2}$ Raphaël Lugan, ${ }^{4}$ \\ Julie Hopkins, ${ }^{5}$ Pierre Frendo, ${ }^{5}$ Alain Bouchereau, ${ }^{2,6}$ Régine Delourme, ${ }^{3}$ Antoine Gravot, ${ }^{2,6}$ and \\ Maria J. Manzanares-Dauleux ${ }^{1,2}$ \\ ${ }^{1}$ AGROCAMPUS OUEST, UMR1349 IGEPP, F-35042 Rennes, France; ${ }^{2}$ Université Européenne de Bretagne, France; ${ }^{3}$ INRA, \\ UMR1349 IGEPP, F-35653 Le Rheu, France; ${ }^{4}$ Institut de Biologie Moléculaire des Plantes, CNRS-UPR2357, F-67084 \\ Strasbourg, France; ${ }^{5}$ Institut Sophia Agrobiotech UMR INRA 1355-CNRS 7254-Université de Nice-Sophia Antipolis, \\ F-06903 Sophia-Antipolis, France; ${ }^{6}$ Université Rennes 1, UMR1349 IGEPP, F-35000 Rennes, France
}

Submitted 10 February 2012. Accepted 6 July 2012.

\begin{abstract}
Clubroot disease affects all Brassicaceae spp. and is caused by the obligate biotroph pathogen Plasmodiophora brassicae. The development of galls on the root system is associated with the establishment of a new carbon metabolic sink. Here, we aimed to deepen our knowledge of the involvement of primary metabolism in the Brassica napus response to clubroot infection. We studied the dynamics and the diversity of the metabolic responses to the infection. Root system metabotyping was carried out for 18 rapeseed genotypes displaying different degrees of symptom severity, under inoculated and noninoculated conditions at 42 days postinoculation (dpi). Clubroot susceptibility was positively correlated with clubroot-induced accumulation of several amino acids. Although glucose and fructose accumulated in some genotypes with minor symptoms, their levels were negatively correlated to the disease index across the whole set of genotypes. The dynamics of the metabolic response were studied for the susceptible genotype 'Yudal,' which allowed an "early" metabolic response (established from 14 to 28 dpi) to be differentiated from a "late" response (from 35 dpi). We discuss the early accumulation of amino acids in the context of the establishment of a nitrogen metabolic sink and the hypothetical biological role of the accumulation of glutathione and $S$-methylcysteine.
\end{abstract}

The obligate soilborne biotrophic protist Plasmodiophora brassicae Woronin is the causal agent of clubroot. This root disease affects all Brassicaceae spp. worldwide, including species of agronomic interest such as Brassica rapa, B. napus, and $B$. oleracea. It is characterized by the development of galls on the root system, which can severely impair plant water and nutrient uptake. The $P$. brassicae life cycle is divided into two phases (Kageyama and Asano 2009). The primary phase occurs inside the host root hairs where the pathogen develops into pri-

Corresponding author: M. J. Manzanares-Dauleux;

E-mail: maria.manzanares@agrocampus-ouest.fr

* The $\boldsymbol{e}$-Xtra logo stands for "electronic extra" and indicates that four supplementary tables are published online.

This article is in the public domain and not copyrightable. It may be freely reprinted with customary crediting of the source. The American Phytopathological Society, 2012. mary plasmodia. The secondary phase takes place in both the cortex and stele of the hypocotyl and roots of infected plants. It is associated with the formation of pathogen multinucleate secondary plasmodia, along with cell hypertrophy and hyperplasy in the root. Resting spores are finally released from the infected tissues and can remain viable in the soil for up to 15 years (Mattusch 1977).

Like all obligate biotrophs, $P$. brassicae depends on host assimilates to complete its life cycle. Clubroot development is associated with the establishment of a root metabolic sink, possibly controlled by increased cytokinin levels (Devos et al. 2006; Siemens et al. 2006). Previous studies showed that translocation of carbohydrates from shoots to roots is stimulated in different Brassica spp. during clubroot disease (Keen and Williams 1969b; Mitchell and Rice 1979). In addition, soluble and storage carbohydrates also accumulate in these galls (Keen and Williams 1969a and b; Williams et al. 1968). Similar results were observed in Arabidopsis thaliana, where microscopy studies revealed the presence of amyloplasts in infected cells (Mithen and Magrath 1992), and metabolic analysis demonstrated increased glucose, fructose and starch levels in galls (Brodmann et al. 2002; Evans and Scholes 1995). These metabolic changes were also corroborated by transcriptomic studies in Arabidopsis, where a large number of genes involved in sugar transport and metabolism were differentially expressed in infected plants compared with controls (Siemens et al. 2006). Siemens and associates (2011) linked disease development to the activity of invertases in infected Arabidopsis root tissues. Accordingly, the root-specific overexpression of proteins acting as extracellular invertase inhibitors resulted in decreased disease susceptibility. Galls are also characterized by an accumulation of trehalose, a dissacharide usually found at low amounts in higher plants (Paul et al. 2008) and which appears to be synthesized by the pathogen during clubroot disease (Brodmann et al. 2002). Exogenous supply of trehalose results in the accumulation of the intermediate trehalose-6-phosphate, leading to deep alterations of carbohydrate signaling and metabolism (Paul et al. 2008), including the accumulation of starch (Wingler et al. 2000). Trehalose interference with plant physiological processes is genotype dependent and can benefit the pathogen (Gravot et al. 2011). However, in contrast to the well-characterized changes in carbohydrates during clubroot disease, little information is available about nitrogen metabolism. Williams and associates (1968) showed that total nitrogen, protein, and 
amino acid contents increase in cabbage galls during clubroot disease. More recently, Jubault and associates (2008) reported a large accumulation of proline in infected Arabidopsis roots, which could be associated with a response to water limitation caused by the loss of functional roots.

The aim of this study was to deepen our understanding of the involvement of primary metabolism in the response to clubroot infection through i) an analysis of the diversity of the metabolic responses to clubroot infection in a genetically diverse range of host plants and ii) a dynamic analysis of the metabolic response to clubroot infection. This study was focused on the $P$. brassicae-B. napus pathosystem because of both the devastating worldwide impact of clubroot on rapeseed and the availability of a large number of germplasm resources displaying a wide range of clubroot symptom severity (Manzanares-Dauleux et al. 2000a and b, 2003). First, we performed metabotyping on a set of 18 rapeseed genotypes selected from a broad range of the species gene pool. This study was made at a late time point in the infection cycle to maximize the number of clubroot-induced perturbations in the whole set of genotypes. A combination of chromatographic techniques dedicated to targeted-metabolic profiling enabled the analysis of 37 identified compounds, including soluble carbohydrates, amino acids, organic acids, and polyols, in addition to five unidentified compounds. The metabolic data were then correlated with the extent of disease symptoms. This enabled the perturbations in primary metabolism associated with disease susceptibility in different genotypes to be identified. Second, we investigated the dynamics of the metabolic response to clubroot infection in a susceptible genotype over a time course encompassing the secondary phase of the infection. Pathogen development was characterized during this time study through in planta DNA quantification and histopathological observations. Finally, "early" (established from 14 to 28 days postinoculation [dpi]) and "late" (from $35 \mathrm{dpi}$ ) pathogenesisrelated metabolic fingerprints were identified.

\section{RESULTS}

Clubroot symptom severity in the rapeseed genotypes.

The disease index (DI) of the 18 genotypes investigated ranged from 28 to 95 , reflecting a wide range of symptoms
(Fig. 1). Multiple comparison tests differentiated six overlapping groups according to their DI $(P<0.05)$. The group showing the lowest DI (from 28 to 50) included the winter oilseed rape (WOSR) cultivars Darmor- $b z h$, Express, Mendel, Hektor, Tosca, and Aviso. Eight genotypes were classified in the most susceptible group (DI from 88 to 95), including cvs. Titus, Mar, Tenor (WOSR genotypes), Wuhan4, Westar, Duplo (spring oilseed rape [SOSR] genotypes), and Liho (fodder rape genotype) and Brown sarson $\times$ cauliflower (synthetic rapeseed). We defined an arbitrary cut-off point of DI $=50$ to separate the genotypes displaying the least severe symptoms ("lowDI" group), from those displaying the highest symptom levels ("high-DI" group).

\section{Multivariate analyses of the metabolic responses to clubroot infection in the set of rapeseed genotypes in relation with the $D I$.}

Targeted profiling of 35 primary metabolites (amino acids, sugars, organic acids, and polyols) was performed in methanolic extracts of the roots of inoculated and noninoculated plants of the 18 genotypes at $42 \mathrm{dpi}$. The analysis of chromatograms also revealed the presence of seven initially untargeted molecules. Additional chemical investigations by liquid chromatography tandem mass spectrometry (LC-MS/MS) (details below) led to the identification of two of those molecules as $S$-methylcysteine (SMC) and oxidized glutathione (GSSG). The five remaining unidentified compounds are referred to hereafter as molecules X1 to X5. The complete quantitative dataset is given in Supplementary Table S2. Variation within the metabolic profiles corresponding to inoculated and noninoculates plants of the 18 rapeseed genotypes was investigated using principal component analysis (PCA) (Fig. 2). Eigen values of principal component (PC)1 and $\mathrm{PC} 2$ represented 41.3 and $13.7 \%$, respectively, of the total variance; the variables associated with PC1 were mainly amino acids. Regardless of the genotype, the metabolic profiles of the noninoculated plants were very similar and characterized by low amino acid contents. Among the inoculated plants, PC1 distinguished the high-DI group from the low-DI group. All inoculated genotypes within the high-DI group were associated with increased amino acid contents and formed three main subgroups: $1=$

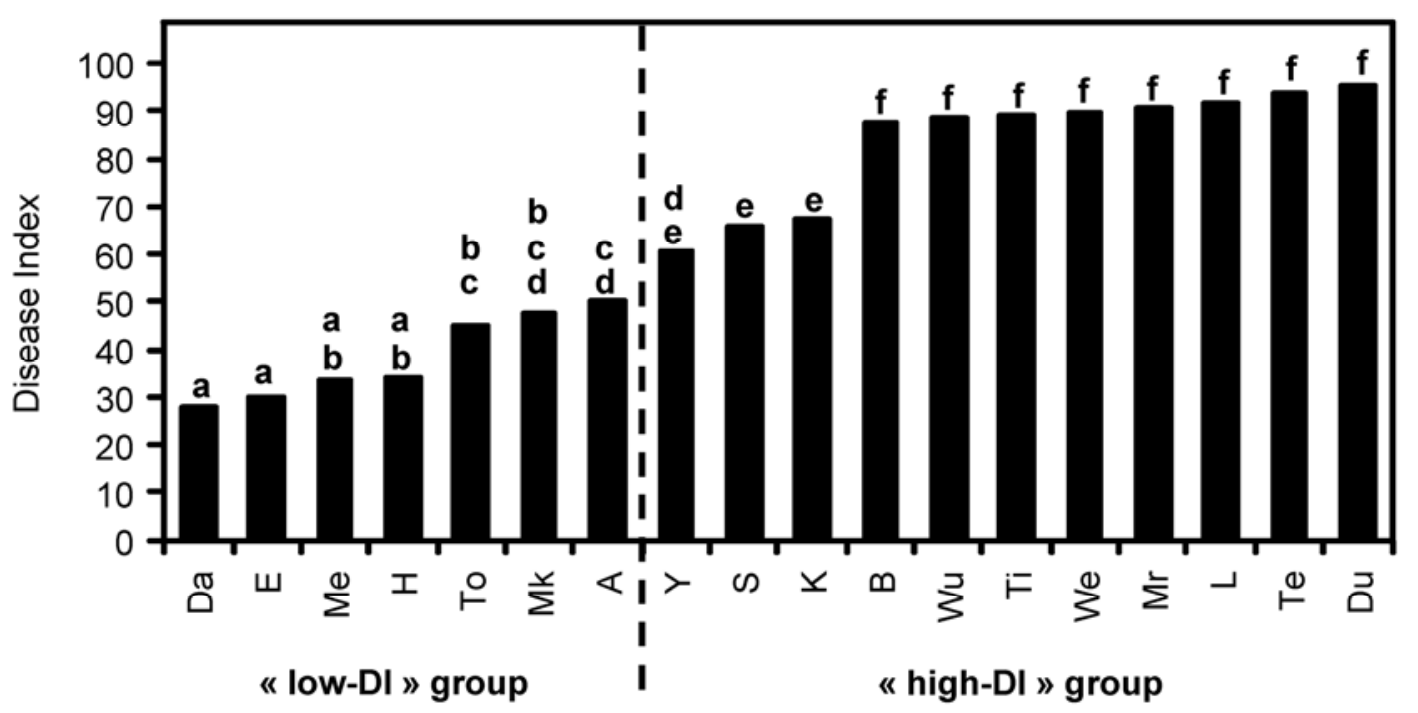

Fig. 1. Disease index (DI) recorded for the 18 Brassica napus genotypes at 49 days after inoculation with the eH isolate of Plasmodiophora brassicae. Data were obtained from four replicates. Same letters indicate nonsignificant differences from Student Newman Keuls (SNK) tests at $P=0.05$. The "high-DI" group was separated from the "low-DI" group using the arbitrary value of DI = 50. Da = 'Darmor- $b z h$ ', E = 'Express', Me = 'Mendel', H = 'Hektor', To = 'Tosca', Mk = 'Markus', A = 'Aviso', Y = 'Yudal', S = SCRI57, K = 'Krapphauser', B = Brown sarson $\times$ cauliflower, Wu = 'Wuhan4', Ti = 'Titus', We = 'Westar', Mr = 'Mar', L = 'Liho', Te = 'Tenor', and Du = 'Duplo'. 
Brown sarson $\times$ cauliflower; 2 = cvs. Liho, Duplo, and Mar; and 3 = cvs. Titus, Tenor, Krapphauser, Yudal, Westar, and Wuhan4. Differences in metabolic profiles between inoculated and noninoculated plants of most of the genotypes in the low-DI group were very weak, with the exception of cvs. Tosca, Darmor- $b z h$, and Markus.

Next, the metabolic response of each genotype was investigated by calculating their relative metabolic content as the logarithmic ratio of the metabolic content of inoculated plants over the metabolic content of noninoculated plants (Fig. 3). Hierarchical clustering analysis (HCA) separated the low-DI group from the high-DI group, with the exception of 'Tosca', which was classified into the high-DI group; it should be noted, however, that 'Tosca' showed a DI close to the arbitrary cut-off point value of 50 .

When HCA was carried out on the metabolites as objects, five main metabolic groups (A to E) were identified. We then calculated Spearman correlation coefficients $(P<0.05)$ be- tween the DI and the relative content of each metabolite. The majority of metabolites in groups $\mathrm{A}, \mathrm{B}$, and $\mathrm{C}$ accumulated significantly more in inoculated plants compared with noninoculated controls $(P<0.05)$ in the high-DI group. Increased levels of these metabolites were also observed sporadically in the low-DI group. Metabolites in groups $\mathrm{A}, \mathrm{B}$, and $\mathrm{C}$ also showed positive Spearman correlation coefficients (mainly amino acids and trehalose) with the DI. The most important differences in metabolic contents between inoculated and noninoculated plants were observed in group A, for SMC, X5, and trehalose. This high relative change was mainly due to the fact that their levels were very low in noninoculated plants. For example, trehalose contents measured as high as $195 \mu$ mol per gram of dry weight (DW) in inoculated samples of 'Tenor' compared with only $1.3 \mu \mathrm{mol}$ per gram of DW in noninoculated samples. Amino acids (a total of 17) were predominant in groups $\mathrm{B}$ and $\mathrm{C}$, with significantly higher levels in inoculated high-DI genotypes compared with their controls. In group D,
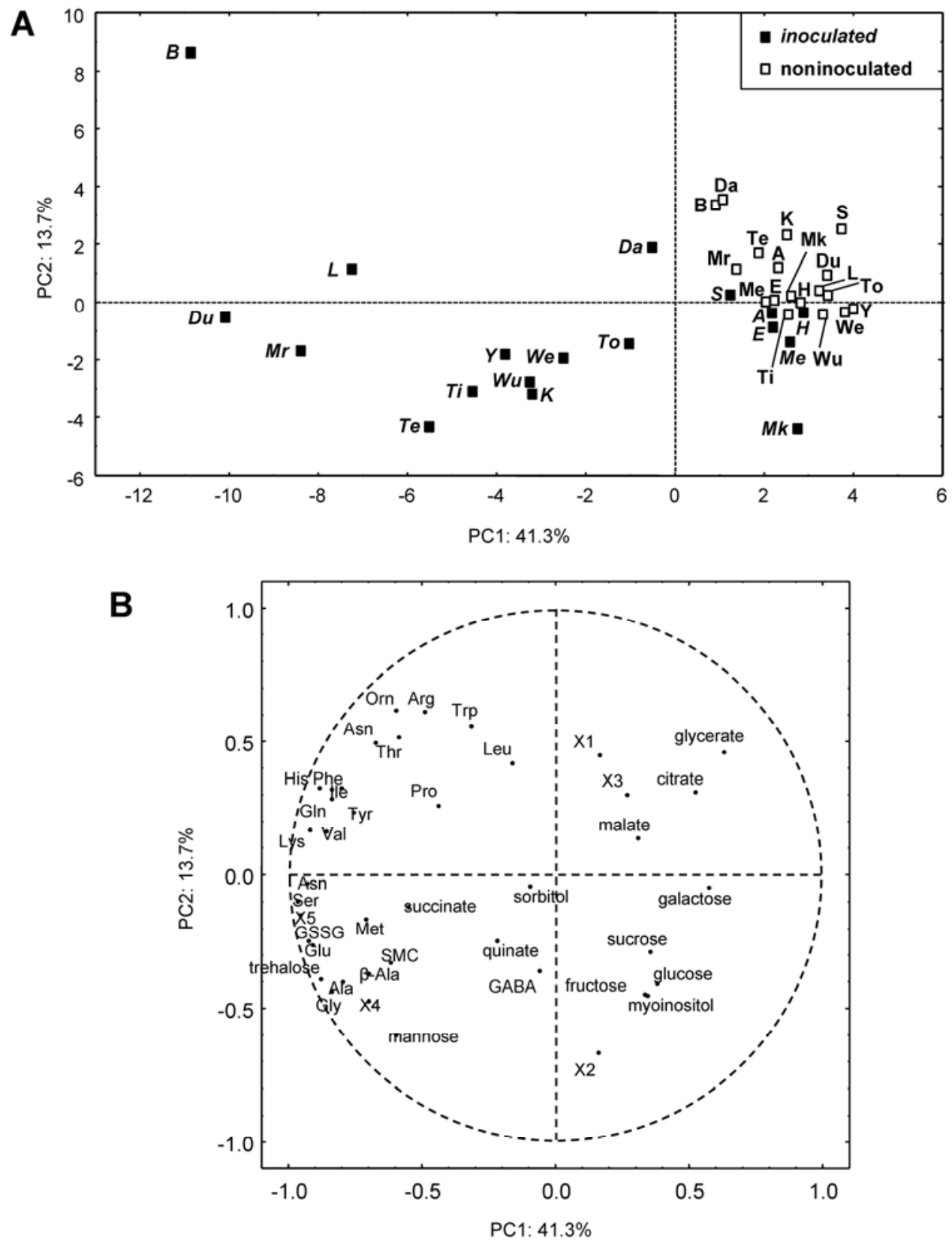

Fig. 2. Principal component (PC) analysis of inoculated and noninoculated genotypes at 42 days postinoculation. The two major PC that accounted for $55.0 \%$ of the variance have been plotted. A, Score plot (genotypes). B, Loading plot (metabolites). GSSG $=$ glutathione disulfide, SMC $=S$-methylcysteine. 


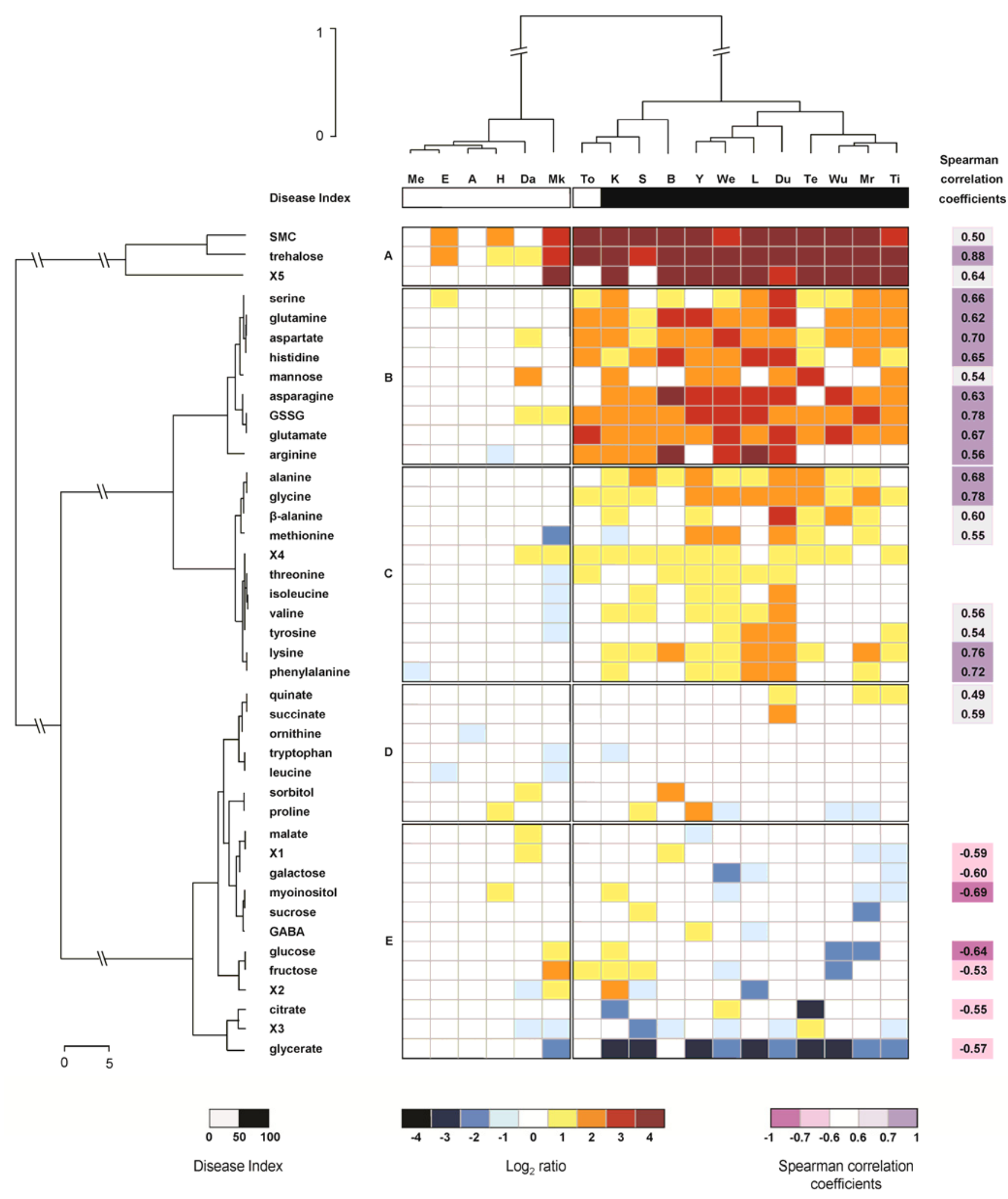

Fig. 3. Hierarchical clustering analysis of the "relative metabolic contents" of roots at 42 days postinoculation by Plasmodiophora brassicae in a set of 18 Brassica napus genotypes. For each genotype and each metabolite, data were expressed as the mean of the logarithmic ratio of inoculated over noninoculated values ( $n=4$; GSSG: glutathione disulfide and SMC: $S$-methylcysteine). Clustering of the 18 genotypes and the 42 metabolites was performed based on Manhattan distances, and with Ward hierarchical clustering using the whole dataset. Only significant differences according to Mann-Whitney $U$ tests $(P<$ $0.05)$ were displayed on the heat map. The disease index (DI) is also indicated for each genotype. Significant Spearman correlation coefficients $(P<0.05, n=18)$ between the "relative metabolic contents" and DI are also shown. $\mathrm{Me}=$ 'Mendel', $\mathrm{E}=$ 'Express', A = 'Aviso', H = 'Hektor', Da = 'Darmor- $b z h$ ', Mk $=$ 'Markus', $\mathrm{To}=$ 'Tosca', $\mathrm{K}=$ 'Krapphauser', Te = 'Tenor', Wu = 'Wuhan4', S = SCRI57, Ti = 'Titus', Mr = 'Mar', We = 'Westar', Y = 'Yudal', L = 'Liho', Du = 'Duplo', and $\mathrm{B}=$ Brown sarson $\times$ cauliflower. 
only a few significant changes were detected which correlated with the genotypes investigated. Finally, group E contained six non-amine metabolites (including glucose, fructose, and glycerate), which correlated negatively with the DI. In the high-DI group, on average, glycerate was depleted during clubroot infection $(\Delta=9 \mu \mathrm{mol}$ per gram of DW). Glucose contents increased significantly in cvs. Krapphauser $(\mathrm{DI}=67)$ and Markus (DI = $48)$ and decreased significantly in cvs. Mar (DI = 91) and Wuhan4 (DI = 89).

\section{Linear discriminant analysis within the low-DI and high-DI groups.}

Linear discriminant analysis was used to identify the metabolites which better separated the inoculated from the noninoculated plants within the previously determined low-DI and highDI groups. The six most discriminating metabolites are shown in Table 1, and the rest of the results are included in Supplementary Table S3. Glutamine was identified in both groups. In the high-DI group, asparagine, arginine, and trehalose were the most discriminating markers of the response to clubroot infection. In the low-DI group, the most characteristic-discriminating metabolites were glucose and fructose.

\section{Dynamics of the metabolic response}

to clubroot infection in relation to pathogen DNA amount.

In order to follow the development of metabolic responses to the infection process over time, the dynamics of clubroot infection was monitored in 'Yudal' roots at 14, 21, 28, 35, and $42 \mathrm{dpi}$. This genotype belonged to the high-DI group in the previous "18 genotypes" experiment. Progression of the infection was monitored using histopathological observations combined with in planta quantification of pathogen DNA. At each time point, amount of pathogen DNA was compared with amount of host plant DNA to calculate the relative pathogen DNA.

Multiple comparisons of the mean "relative pathogen DNA" throughout the time course $(P<0.05)$ revealed two distinct periods (Fig. 4A): a low level of relative pathogen DNA from 14 to 28 dpi which increased significantly from 28 to 35 dpi. During the first period, the relative pathogen DNA increased slowly from a ratio of 0.04 to 0.52 . Root histological observations showed the presence of secondary plasmodia in the cortex and stele of the roots as soon as 14 dpi (data not shown). From $21 \mathrm{dpi}$, an increasing number of secondary plasmodia were distinguished inside the root system, in parallel with the development of secondary xylem and phloem. At $28 \mathrm{dpi}$, infected cells in the cortex were clearly disorganized and hyper-

Table 1. Coefficients of linear discriminant function obtained from the linear discriminant analysis between clubroot-inoculated and noninoculated rapeseed samples in the low-disease index (DI) and high-DI groups ${ }^{\mathrm{a}}$

\begin{tabular}{lc}
\hline Metabolite & Coefficient of linear discriminant function \\
\hline Low-DI & \\
GSSG & 15.8 \\
Glucose & -12.1 \\
Histidine & -8.8 \\
Glutamine & 8.0 \\
Isoleucine & 7.6 \\
Fructose & 7.4 \\
High-DI & \\
Asparagine & -4.9 \\
Arginine & 3.7 \\
Trehalose & -3.5 \\
Glutamine & 2.7 \\
SMC & -1.8 \\
X4 & -1.4 \\
\hline
\end{tabular}

${ }^{\mathrm{a}} \mathrm{GSSG}=$ oxidized glutathione, SMC $=S$-methylcysteine, and X4 = unidentified compound. trophied (Fig. 4C) and the clubs became apparent to the naked eye. From 28 to $35 \mathrm{dpi}$, the relative pathogen DNA increased significantly (reaching 2.27 , hereafter referred to as the "developmental burst") and remained stable up to 42 dpi. From 35 dpi, histological observations showed the presence of multinucleate secondary plasmodia in infected cells (Fig. 4E).

Primary metabolites were quantified at each time point in the series (Supplementary Table S4). Of the 42 metabolites analyzed at each time point, 31 showed significantly different contents between inoculated and noninoculated plants $(P<$ $0.05)$. Sixteen metabolites had significantly increased or decreased contents at early time points (from 14, 21, or $28 \mathrm{dpi}$, with low relative pathogen DNA) (Fig. 5A), and 15 from late time points (from $35 \mathrm{dpi}$, with high relative pathogen DNA) (Fig. 6A). The logarithmic ratio of metabolic content in inoculated plants versus those in noninoculated plants ("relative metabolic contents") was correlated to relative pathogen DNA using Spearman correlation coefficients. These correlations were calculated for two periods, from 14 to $28 \mathrm{dpi}$ and from 28 to 42 dpi for the early metabolites (Fig. 5A), and from 28 to $42 \mathrm{dpi}$ for the late metabolites (Fig. 6A).

The majority of the metabolites which accumulated in plant extracts in the early time points were amines (a total of 9); for example, glutamate and aspartate from $14 \mathrm{dpi}$, GSSG and asparagine from $21 \mathrm{dpi}$ (Fig. 5B), and X5 from 28 dpi. Trehalose, GSSG, X4, and X5 relative contents were significantly correlated to relative pathogen DNA throughout the entire time course, whereas glutamate, aspartate, and asparagine relative contents were only significantly correlated to relative pathogen DNA from 28 to 42 dpi (Fig. 5A). Significantly lower glycerate contents were also detected in inoculated samples from 21 dpi (Fig. 5C).

Amino acids were also the main metabolites which accumulated significantly from $35 \mathrm{dpi}$. SMC and proline showed the highest levels of accumulation in inoculated plants (Fig 6A). SMC contents in inoculated plants showed a similar pattern to that of pathogen DNA (Fig. 6B), even if no significant correlation was found between the two measurements. Glutamine and proline showed significant correlations with relative pathogen DNA from 28 to 42 dpi. Glucose showed significantly lower contents at $42 \mathrm{dpi}$, due to an inhibition of its accumulation in inoculated samples (Fig. 6C).

GSSG accumulation in root methanolic extracts was found to be an interesting biomarker for clubroot disease. Because glutathione $(\mathrm{GSH})$ was not initially included in the targeted compounds, no special precaution was taken for protecting this compound against oxidation. Subsequently, only GSSG was found in sample extracts, not the reduced form GSH, suggesting that the GSH pool was oxidized during the extraction process. The clubroot-induced accumulation of GSSG in unprotected extracts suggested, nonetheless, that the GSH pool was substantially increased during clubroot infection. To confirm this hypothesis, GSH content was analyzed through a specific procedure for extraction and quantification of GSH (discussed below). Using this method, GSH content was also found to be significantly increased in infected roots at 42 dpi compared with noninfected controls $(P<0.05)$, and the fourfold increase was similar to that previously observed with the AccQTag method (Table 2).

An accumulation of sulfur and nitrogen-rich amino acids was observed in infected roots. To investigate whether this phenomenon could be related to a global accumulation of nitrogen and sulfur in galls, we examined the total nitrogen and sulfur status in clubs at 42 dpi using elementary analysis (Table 2). The total sulfur content was significantly increased in inoculated roots compared with noninoculated controls $(P<$ $0.10)$. Meanwhile, total nitrogen was significantly increased in 
inoculated roots $(P<0.05)$, whereas nitrate contents were similar between inoculated and noninoculated samples.

\section{DISCUSSION}

Metabolic-based clustering of clubroot responses in the set of rapeseed genotypes agrees well

with DI-based classification.

In this study, metabolic profiling of root methanol extracts was used to characterize the response to clubroot infection in a set of rapeseed genotypes selected to represent a broad range of genetic diversity. To date, metabolic profiling has mainly been used as a tool to characterize genetic diversity within collections of genetic resources. In the case of large metabolic datasets, this approach, as previously shown by Del Carpio and associates (2011), provides structures of genetic diversity comparable with those observed using molecular markers. In our study, no clear relationship was highlighted between structures of genetic diversity obtained by using simple-sequence repeat markers (data not shown) or metabolic profiles in the noninoculated samples, possibly due to the low number or the nature of the metabolites investigated. Indeed, chemotaxonomy is mainly performed using components of secondary metabolism which were not considered in this study (Frisvad et al. 2008).

Most of the metabolites showed a relative content positively or negatively correlated with the intensity of symptoms measured by the DI. This global correlation between symptom intensity and metabolic response would suggest common mechanisms of response to the infection among the different genotypes investigated. Therefore, metabolic profiling allows finer char-

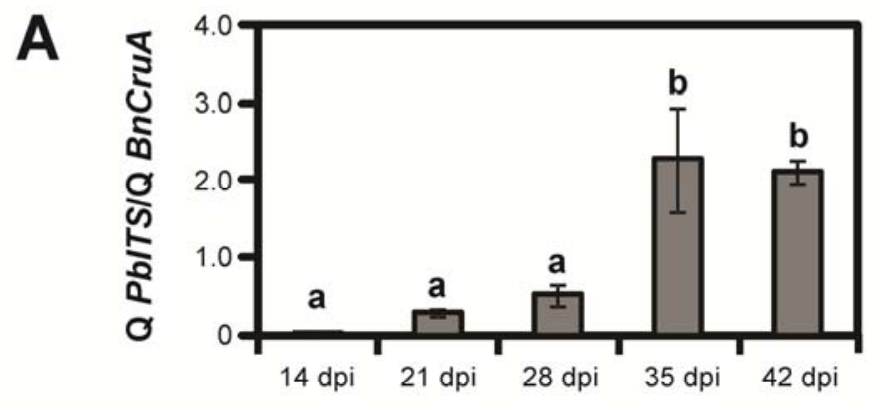

B
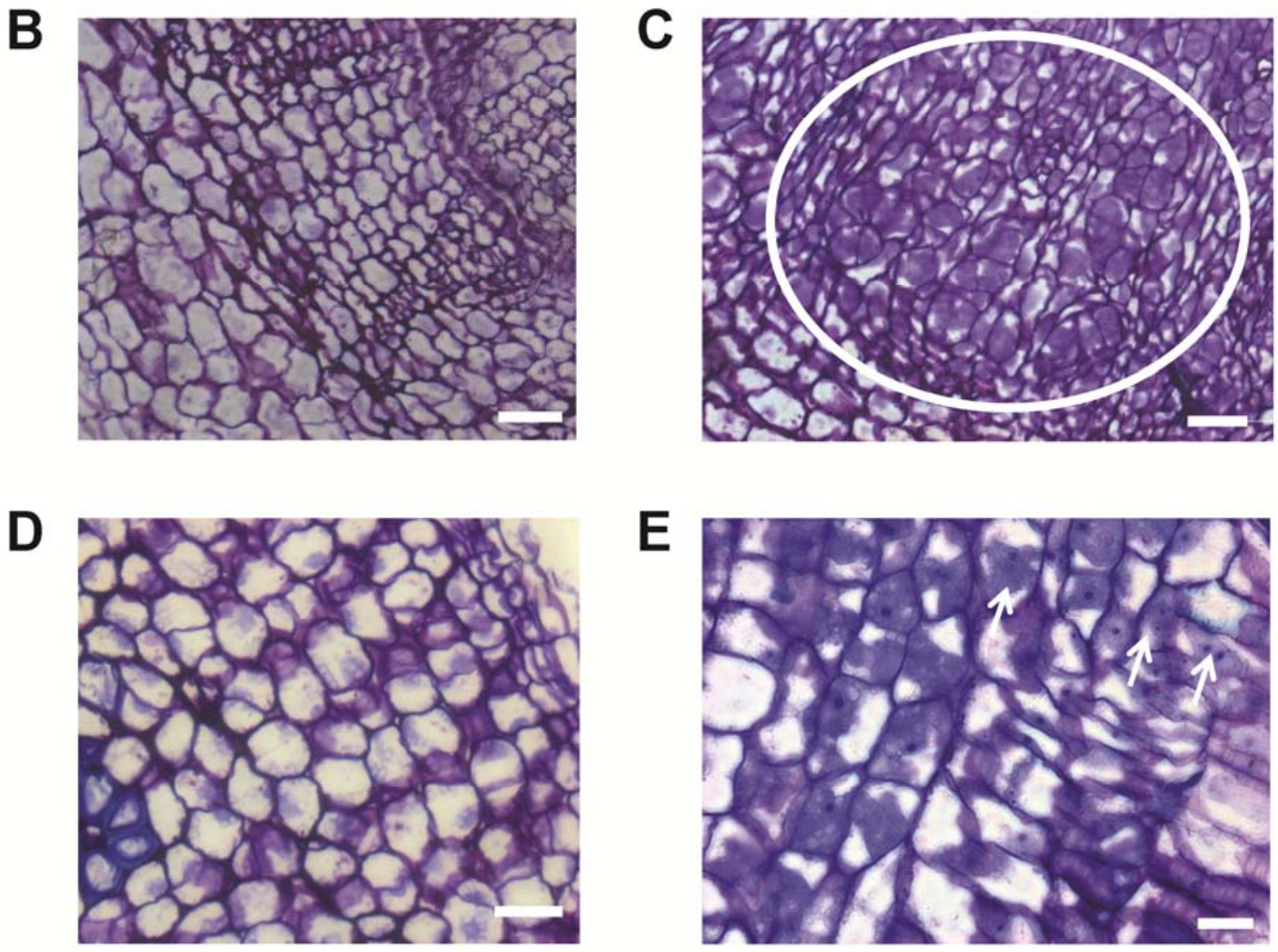

Fig. 4. A, In planta quantification of Plasmodiophora brassicae DNA compared with Brassica napus DNA by quantitative polymerase chain reaction in cv. Yudal. The internal transcribed spacer region of P. brassicae was amplified (PbITS) and compared with the cruciferin A gene of $B$. napus (BnCruA). Samples were analyzed at $14,21,28,35$, and 42 days postinoculation (dpi). Different letters indicate significant differences $(P<0.05)$ from multiple comparison $Z$-value tests.Data are expressed as mean of four replicates \pm standard error. $\mathbf{B}$ to E, Histopathological characterization of clubroot infection in the genotype Yudal, from transversal sections of inoculated and noninoculated roots at different time points after inoculation. B, Control roots at $28 \mathrm{dpi}$. Bars represent $50 \mu \mathrm{m}$. C, Inoculated roots at $28 \mathrm{dpi}$, focused on the cortex. Hypertrophied cells are filled with large secondary plasmodia (white circle). Bars represent $50 \mu \mathrm{m}$. D, Control root at $35 \mathrm{dpi}$. Bars represent $25 \mu \mathrm{m}$. E, Inoculated root at $35 \mathrm{dpi}$, focused on the cortex, where secondary multinucleate plasmodia are visible and indicated by white arrows. Bars represent $25 \mu \mathrm{m}$. 

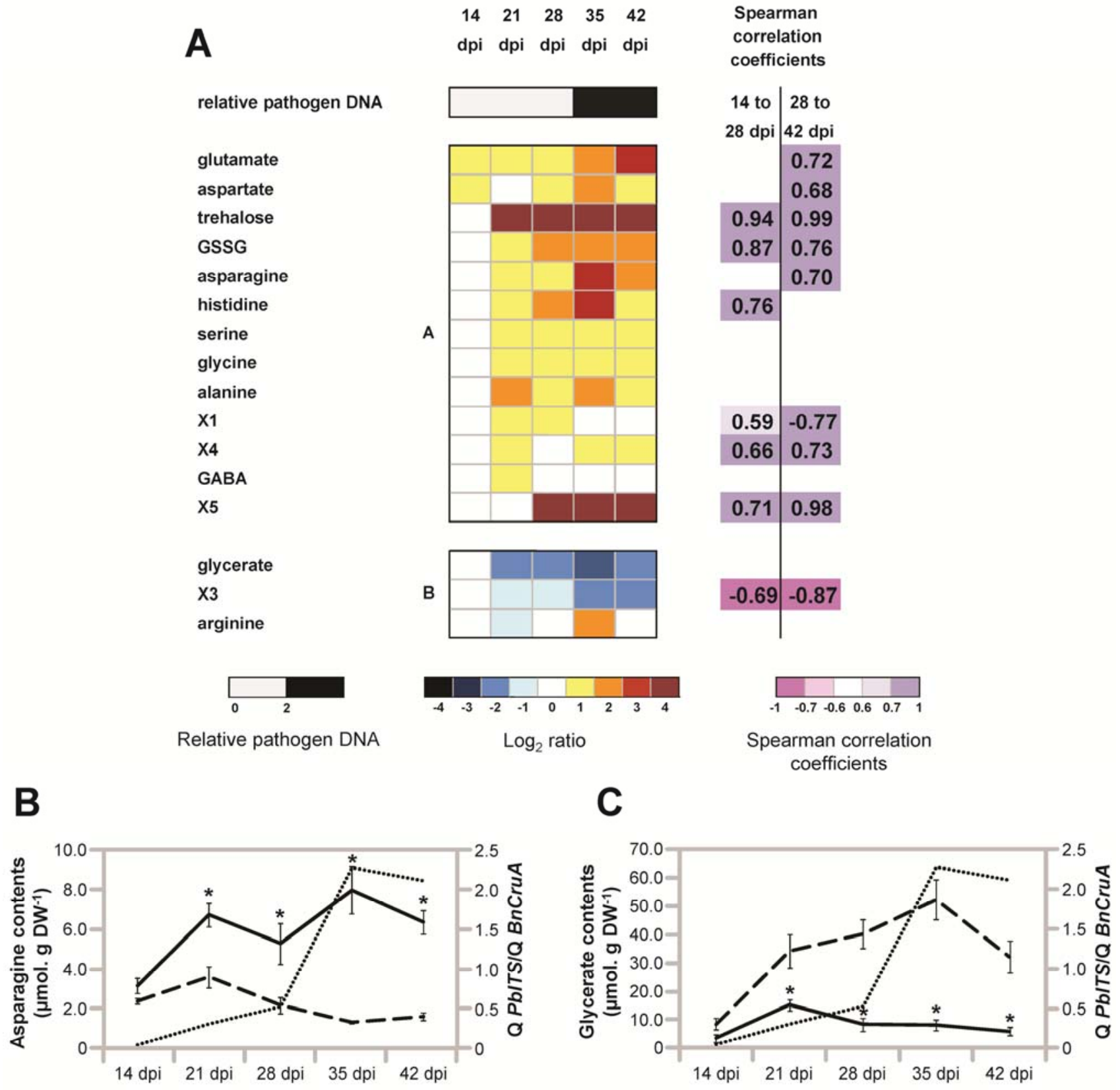

D

E
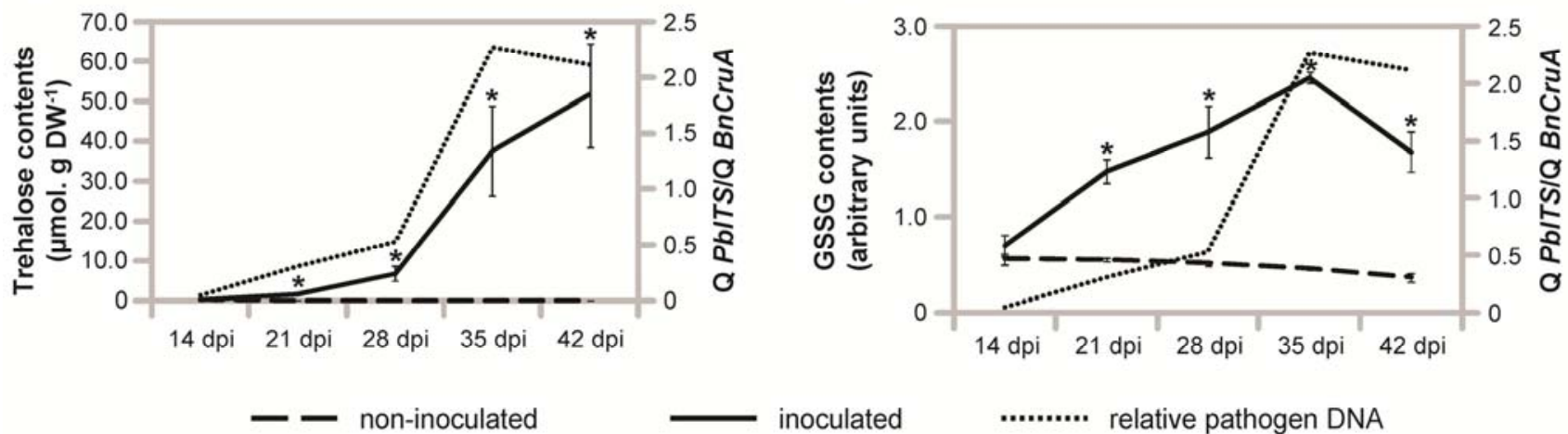

inoculated

relative pathogen DNA

Fig. 5. A, Heat map of the metabolites which accumulated or were depleted significantly between clubroot-inoculated and noninoculated rapeseed plants from 14 to 28 days postinoculation. Significant differences were determined using Mann-Whitney $U$ tests $(P<0.05)$. Data are expressed as the mean of the logarithmic ratio of inoculated over noninoculated values (GSSG: glutathione disulfide). B, Asparagine; C, glycerate; D, trehalose; and E, GSSG contents in inoculated and noninoculated samples at various time points during the infection process, compared with relative pathogen DNA. Data are expressed as mean of four replicates \pm standard error. Symbols $(*)$ indicate statistically significant differences between inoculated and noninoculated samples $($ MannWhitney $U$ test, $P<0.05$ ). 
A

relative pathogen DNA

SMC

proline

glutamine

$\beta$-alanine

succinate

myoinositol

phenylalanine

lysine

leucine

valine

isoleucine

threonine

quinate

citrate

glucose

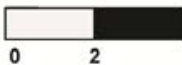

Relative pathogen DNA $\begin{array}{lllll}14 & 21 & 28 & 35 & 42\end{array}$

dpi dpi dpi dpi dpi

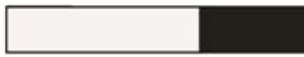

A

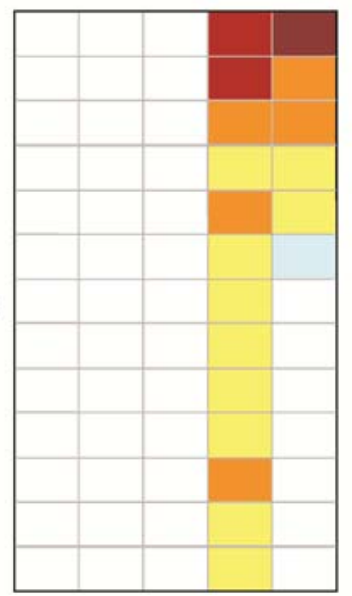

B
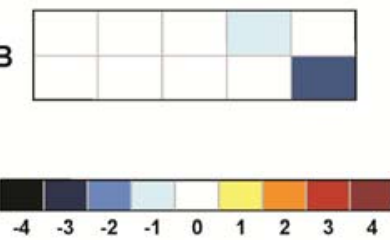

$\log _{2}$ ratio
Spearman

correlation

coefficients

28 to

$35 \mathrm{dpi}$

0.78

0.75

0.71

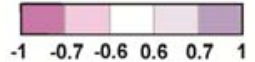

Spearman correlation

coefficients

B

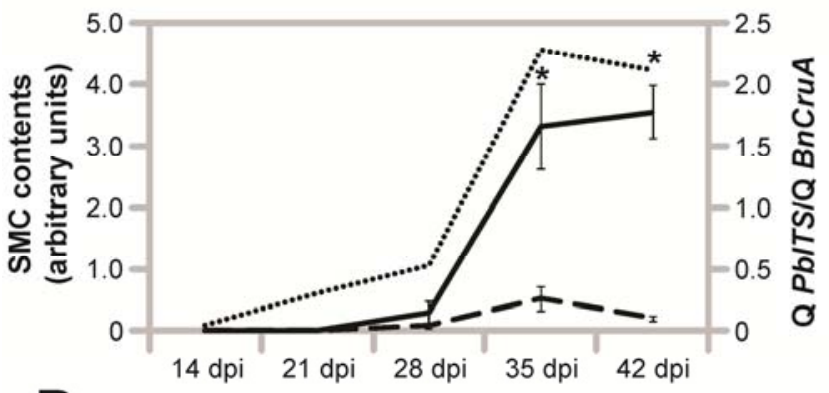

D
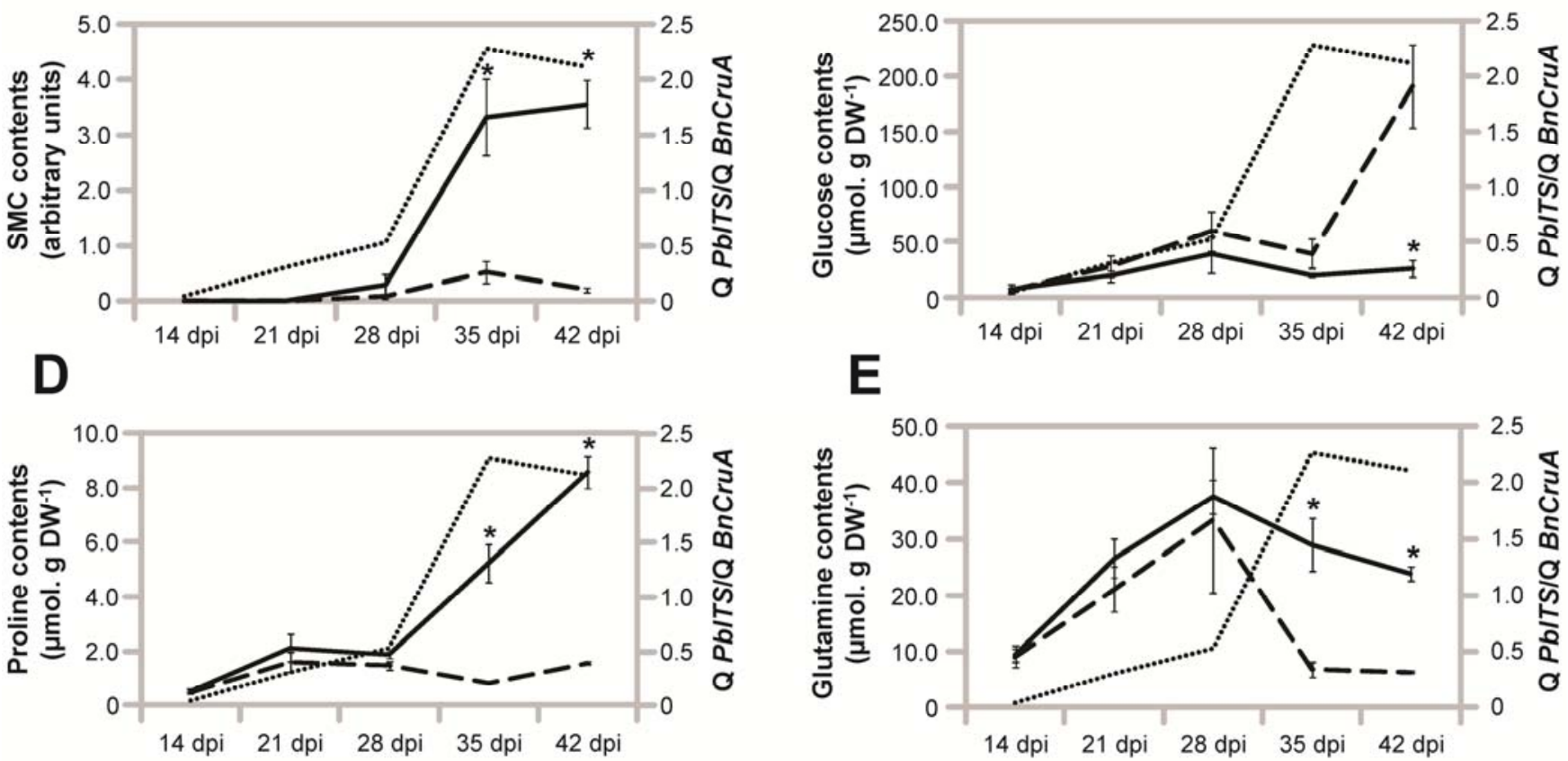

- - non-inoculated

inoculated

relative pathogen DNA

Fig. 6. A, Heat map of the metabolites which had accumulated or were depleted significantly between clubroot-inoculated and noninoculated rapeseed plants from 35 to 42 days postinoculation according to Mann-Whitney $U$ tests $(P<0.05)$. Data are expressed as the mean of the logarithmic ratio of inoculated over noninoculated values $(\mathrm{SMC}=S$-methylcysteine). B, SMC; $\mathbf{C}$, glucose; $\mathbf{D}$, proline; and E, glutamine contents in inoculated and noninoculated samples at various time points during the infection process, compared with relative pathogen DNA. Data are expressed as mean of four replicates \pm standard error. Symbols (*) indicate statistically significant differences between inoculated and noninoculated samples (Mann-Whitney $U$ test, $P<0.05$ ). 
acterization of the plant response to clubroot infection than a DI-based evaluation of the symptoms. For example, the apparent discrepancy between metabolic and DI-based clustering of 'Tosca' could reflect some bias in the visual phenotyping of this genotype, and would require additional investigations at the histological and molecular levels.

\section{Amino acid contents correlate positively with symptoms.}

Increased carbohydrate and amino acid contents are a typical feature in the establishment of trophic relationships between biotrophs and their host plant. Such traits were characteristic in mycorrhizal symbiosis (Kiers et al. 2011) as well as in Arabidopsis roots infected by cyst nematodes (Hofmann et al. 2008, 2010), tumor-inducing Agrobacterium tumefaciens infections (Deeken et al. 2006, Simoh et al. 2009), or infections of Arabidopsis shoots with Rhodococcus fascians (Depuydt et al. 2009). Based on the results obtained in our study, we can now refine this general view of trophic plant-pathogen relationships regarding carbohydrates. Indeed, if only one rapeseed genotype was studied (and depending on the genotype), we could have concluded that clubroot infection induces glucose accumulation, or depletion, or has no effect. Metabolic profiling experiments on clubroot have usually been performed on one or a few genotypes (Ludwig-Müller et al. 2009). In our study, only the analysis of the whole genotype set allowed us to highlight a global negative correlation between the contents of six non-amine metabolites (including glucose, fructose, myoinositol, and glycerate) and clubroot symptom intensity. For glucose and fructose, this negative correlation was related to a clubroot-induced relative accumulation of glucose only in the low-DI group (mean ratio $=1.8$ ), contrasting with a mean ratio of 1.0 in the high-DI group. Accordingly, glucose and fructose were the most discriminating metabolites between inoculated and noninoculated plants within the low-DI group. It would be interesting to investigate the relationship between this trait and low susceptibility (partial re- sistance?) to clubroot. Among the other carbohydrates, only relative trehalose contents showed a high positive correlation with the DI; however, this metabolite is assumed to be of pathogen origin (Brodmann et al. 2002) and, therefore, would reflect a pathogenesis rather that a response-resistant process.

Taking into account rapeseed genetic diversity, the level of variation of 17 amino acids was positively correlated to the DI. This positive correlation was especially prominent for the nitrogen-rich amino acids glutamine and asparagine, which are possibly involved in nitrogen transport from source to sink tissues. This was shown in Orobanche foetida or Xanthomonas campestris (Abbes et al. 2008; Zurbriggen et al. 2009), and may possibly contribute to providing nutrition to the pathogen (Hofmann et al. 2010). Indeed, recent sequencing of the genomes of several biotroph pathogens revealed that genes involved in inorganic sulfur and nitrogen assimilation have been lost (Duplessis et al. 2011; Kemen et al. 2011). Nevertheless, the role of nitrogen in disease development remains to be clarified. Previous studies of different plant diseases showed that increased nitrogen supplies could positively impact disease development but could also enhance plant defense (Snoeijers et al. 2000).

The origin of this increased pool of free amino acids that was associated with a significant increase in total nitrogen $(P<$ $0.05)$ remains elusive. This increased nitrogen content could result from remobilization of shoot amino acids or increased nitrate assimilation. Further quantifications of total nitrogen in shoots from inoculated and noninoculated plants, in parallel with $15 \mathrm{~N}$ tracing experiments and measures of nitrate reductase activity, would be necessary to elucidate this further.

\section{Do higher GSH contents play a favorable role in plant or pathogen development?}

Our analyses showed that GSH accumulation was positively correlated with the DI of the different genotypes investigated

Table 2. Quantification of total N, total S, nitrate, and total glutathione (GSH) in roots of clubroot inoculated and noninoculated 'Yudal' at 42 days postinoculation $^{\mathrm{a}}$

\begin{tabular}{|c|c|c|c|c|}
\hline 'Yudal' & Total N (\%) & Total S (\%) & $\mathrm{NO}_{3}^{-}\left(\mu \mathrm{mol} \mathrm{g} \mathrm{DW}^{-1}\right)$ & Total GSH (nmol g FW $\left.{ }^{-1}\right)$ \\
\hline Noninoculated & $2.0 \pm 0.2$ & $0.57 \pm 0.06$ & $14.4 \pm 2.7$ & $198.2 \pm 16.3$ \\
\hline Inoculated & $4.6 \pm 2.1$ & $0.84 \pm 0.02$ & $15.2 \pm 1.9$ & $858.5 \pm 30.4$ \\
\hline Significant difference & ** & $*$ & $\ldots$ & $* *$ \\
\hline
\end{tabular}

${ }^{\mathrm{a}} \mathrm{DW}=$ dry weight and $\mathrm{FW}=$ fresh weight. Asterisks indicate statistically significant differences between inoculated and noninoculated samples $(*$ and $* *$, Mann-Whitney $U$ test with $P<0.1$ and 0.05 , respectively). Values are means \pm standard error $(n=4)$.

Table 3. Brassica napus genotypes $(n=18)$ used for the study represent different agromorphological types and originate from different countries

\begin{tabular}{|c|c|c|c|}
\hline Genotype & Varietal type $^{a}$ & Type $^{\text {b }}$ & Country of origin \\
\hline 'Aviso' & $\mathrm{L}$ & WOSR & Denmark \\
\hline Brown sarson $\times$ cauliflower & SYN & $\ldots$ & India \\
\hline 'Darmor-bzh' & $\mathrm{L}$ & WOSR & France \\
\hline 'Duplo' & $\mathrm{L}$ & SOSR & Germany \\
\hline 'Express' & $\mathrm{L}$ & WOSR & Germany \\
\hline 'Hektor' & $\mathrm{L}$ & WOSR & Sweden \\
\hline 'Krapphauser' & $\mathrm{L}$ & WOSR & Germany \\
\hline 'Liho' & $\mathrm{L}$ & FR & Germany \\
\hline 'Mar' & $\mathrm{L}$ & WOSR & Poland \\
\hline 'Markus' & $\mathrm{L}$ & WOSR & France \\
\hline 'Mendel' & $\mathrm{H}$ & WOSR & Germany \\
\hline SCRI57 & $\mathrm{L}$ & FR & Great Britain \\
\hline 'Tenor' & $\mathrm{L}$ & WOSR & France \\
\hline ‘Titus' & $\mathrm{L}$ & WOSR & France \\
\hline 'Tosca' & $\mathrm{L}$ & WOSR & Sweden \\
\hline 'Westar' & $\mathrm{L}$ & SOSR & Canada \\
\hline 'Wuhan4' & $\mathrm{L}$ & SOSR & China \\
\hline 'Yudal' & $\mathrm{L}$ & SOSR & Korea \\
\hline
\end{tabular}

${ }^{\mathrm{a}} \mathrm{L}=$ line, $\mathrm{H}=$ hybrid, $\mathrm{SYN}=$ synthetic rapeseed.

${ }^{\mathrm{b}}$ WOSR $=$ winter oilseed rape, $\mathrm{SOSR}=$ spring oilseed rape, $\mathrm{FR}=$ fodder rape. 
and also highly correlated with pathogen development during both early (14 to $28 \mathrm{dpi}$ ) and late ( 35 to $42 \mathrm{dpi}$ ) phases of the secondary infection.

Beyond its potential interest as a biomarker of the pathogenic process, the biological significance of GSH accumulation in infected galls remains unclear. This compound is involved in plant defense against biotic stress; for example, in powdery mildew-resistant oat and barley genotypes (Vanacker et al. 1999, 2000). This molecule plays a central role in the detoxification of reactive oxygen species (ROS) through the GSH-ascorbate cycle, and reacts directly with peroxides in a reaction which is catalyzed by GSH S-transferase (GST) (Noctor and Foyer 1998; Noctor et al. 2011). Indeed, transcriptomic and proteomic changes in clubroot-susceptible Arabidopsis (Agarwal et al. 2011; Devos et al. 2006) and B. napus (Cao et al. 2008) were associated with a significantly higher abundance of transcripts and proteins involved in ROS detoxification and, among them, GST. Modifications of the redox signaling observed during the interaction could be linked to plant basal defense mechanisms.

In addition to its involvement in plant resistance against pathogens, GSH could be involved in maintaining redox potential needed for cell division (Vivancos et al. 2010) and the metabolic modifications occurring during gall development and functioning. In this context, GSH may contribute to clubroot disease development through positive regulation of auxin metabolism (Bashandy et al. 2010; Koprivova et al. 2010). Indeed, previous experiments in $B$. rapa showed that inhibition of auxin transport results in decreased clubroot symptoms (Devos and Prinsen 2006). GSH accumulation has been demonstrated to be positively related to the infection processes in plant nematode interactions and in nitrogen-fixing symbiosis (Baldacci-Cresp et al. 2012; Frendo et al. 2005). To refine the understanding of the GSH metabolism during clubroot development, it would now be important to clarify the actual redox status of this molecule in root tissues. In parallel, possible positive or negative roles played by GSH accumulation on the pathogenic process have to be tested through a combination of pharmacological (inhibitors of GSH synthesis) and genetic (clubroot phenotyping on GSH-defective Arabidopsis mutants) approaches.

\section{Is there a role for SMC, an unusual metabolite in Brassicaceae spp., in clubroot disease?}

Brassica spp. are well-characterized by the presence of $S$ methylcysteine sulfoxide (SMCO), an antinutritional compound causing anemia in ruminants (Paul et al. 1986). However, only a few studies focused on SMC, a molecule rarely described in plant species (Pate et al. 1995), usually found in high amounts in Fabaceae seed, where it contributes to the transport of reduced sulfur (Jones et al. 2004). Interestingly, we measured a pronounced accumulation of this molecule in rapeseed galls. To our knowledge, this is the first report of induced accumulation of SMC during biotic stress. Moreover, this metabolite also appears to be specific to clubroot infection in rapeseed, because it has never been detected in ultra-performance liquid chromatography- diode array detection (UPLC-DAD) chromatograms of clubroot-infected Arabidopsis in our laboratory. Its origin remains unknown but the absence of a correlation between the relative SMC content and relative pathogen DNA suggests that it is not of pathogen origin. In B. napus, it is not yet known whether there is a relationship between the SMCO and SMC biosynthesis pathways. In Arabidopsis, one biosynthetic pathway for SMC was characterized in which methanethiol $\left(\mathrm{CH}_{3} \mathrm{SH}\right)$ reacted with activated serine ( $O$-acetylserine) to form SMC (Rébeillé et al. 2006).

Thus, SMC accumulation in rapeseed genotypes could simply be associated with an increased synthesis of methane- thiol during clubroot disease. Methanethiol could result from methylation of hydrogen sulfide (resulting from the cysteine desulfhydrase pathway or the sulfite reduction pathway (Jacob et al. 2008) or from $\gamma$-cleavage of methionine (Rébeillé et al. 2006). SMC could also serve as a vacuolar storage molecule (Rébeillé et al. 2006). Finally, these authors also suggested that this molecule may constitute a reservoir of methyl and sulfide groups, which can be used for the synthesis of other metabolites; for example, the methyl group could be incorporated into methionine (Giovanelli et al. 1980).

\section{Toward the identification of relationships between clubroot-associated metabolic response and pathogen development.}

Quantification of pathogen DNA in the genotype Yudal enabled pathogen development to be monitored from 14 to $42 \mathrm{dpi}$, even at time points when symptoms were not yet visible. Although DNA yields were not necessarily homogeneous throughout pathogen development, in planta quantification was corroborated by high positive Spearman correlation coefficients $(0.94$ from 14 to $28 \mathrm{dpi}, 0.99$ from 28 to $42 \mathrm{dpi}, P<0.05)$ between relative pathogen DNA and relative trehalose contents (reported to be supposedly of pathogen-origin) (Brodmann et al. 2002). Moreover, cDNA-based in planta quantification of $P$. brassicae in $B$. rapa roots, monitored during a time-course experiment including the same time points as in our study, also showed a similar evolution (Schuller and Ludwig-Müller 2006).

Using this approach, hypotheses could be developed on the "causal" and "reactive" relationships between metabolite and pathogen contents over the time course investigated. Interestingly, the relative contents of glutamate, aspartate, and asparagine were positively correlated to relative pathogen DNA from 28 to $42 \mathrm{dpi}$, even if their accumulation was detected from 14 or $21 \mathrm{dpi}$. This suggests that the increased pool of amino acids preceded the "developmental burst" of the pathogen and, thus, may appear to have a causal link to pathogenesis. These metabolites could be used as biomarkers for phenotype prediction, as suggested by Steinfath and associates (2010). Others, like trehalose and GSH, which show a positive correlation with relative pathogen DNA, may have a reactive link with pathogenesis and are possibly synthesized by the pathogen. To confirm and extend these results, it would be interesting now to investigate the early physiological responses in host genotypes showing different levels of resistance and to enlarge the range of $P$. brassicae pathotypes studied, because natural field isolates can consist of different pathotypes (Manzanares-Dauleux et al. 2001).

\section{Conclusion.}

Previous studies have shown the impact of clubroot infection on the carbohydrate metabolism in members of the family Brassicaceae. Our work, broadening the spectrum of both profiled primary metabolites and plant genotypes (from clubrootresistant to highly susceptible genotypes), highlights the fact that clubroot infection can also have an even larger impact on the metabolism of amino acids in clubroot-susceptible plants. Several amines were found to be accumulated from the early stages of the infection and - unlike carbohydrates-were positively correlated to clubroot susceptibility levels among different plant genotypes, suggesting the importance of nitrogen remobilization for the development of galls.

\section{MATERIALS AND METHODS}

\section{Plant and pathogen material.}

A set of $18 \mathrm{~B}$. napus genotypes was selected from an INRA rapeseed-work collection (Brassica Center for Genetic Re- 
sources, INRA, Le Rheu, France). This set includes accessions belonging to different agro-morphological types, seed quality profiles, and origins, with 11 WOSR, four SOSR, two fodder rape genotypes, and a synthetic rapeseed (Table 3 ). The Korean SOSR genotype 'Yudal' was susceptible to all the isolates of $P$. brassicae tested in the laboratory (Manzanares-Dauleux et al. 2000b)

The selection isolate eH (Fähling et al. 2003), belonging to pathotype 1 , was used in all experiments. The isolate is maintained on roots of the universal susceptible host Chinese cabbage (B. rapa subsp. pekinensis 'Granaat' [ECD5]). In each clubroot test, the host differential set established by Somé and associates (1996) (B. napus subsp. oleifera 'Nevin' [ECD6], B. napus subsp. rapifera 'Wilhelmsburger' [ECD10], and B. napus subsp. oleifera [Brutor]) was used to characterize and check isolate pathogenicity profiles at $49 \mathrm{dpi}$. Inoculated and noninoculated ECD5 were used as controls.

\section{Clubroot tests.}

Two different clubroot tests were carried out: the first involved the set of 18 genotypes (referred to as the 18-genotypes experiment) sampled at $42 \mathrm{dpi}$, when symptoms were well established; the second consisted of a time-course study of the clubroot-susceptible genotype 'Yudal' at 14, 21, 28, 35, and 42 dpi (referred to as the 'Yudal' experiment). Plants were grown under controlled conditions (16 h of light at $22^{\circ} \mathrm{C}$ and $8 \mathrm{~h}$ of darkness at $18^{\circ} \mathrm{C}$ ) in plates filled with a mixture of two-thirds compost and one-third vermiculite. Plants were inoculated with the $\mathrm{eH}$ isolate 7 days after sowing according to ManzanaresDauleux and associates (2000a); the plants were inoculated with $1 \mathrm{ml}$ of a suspension of resting spores at $10^{7}$ spores $\mathrm{ml}^{-1}$ (inoculated plants) or with $1 \mathrm{ml}$ of distilled water (noninoculated plants). Each experiment consisted of two independent biological repeats. A randomized complete block design was used for each repeat; two replicates of 18 plants per sample (genotypeinoculation) were performed for the 18-genotypes experiment and two replicates of 27 plants per sample were performed for the 'Yudal' experiment (54 plants for the first kinetic point at 14 dpi). Plant material was always sampled at the end of the dark phase, thoroughly rinsed in tap water, and then briefly dried with paper towel. Samples were frozen in liquid nitrogen and stored at $-80^{\circ} \mathrm{C}$ until analyzed. Six extra plants per genotype were included in the experimental design to record symptoms at 49 dpi, using the scale described by ManzanaresDauleux and associates (2000a). This allowed a DI to be calculated for each genotype according to Buczacki and associates (1975).

\section{Metabolic profiling.}

Samples were ground to a fine powder in liquid nitrogen and freeze dried. Nonstructural carbohydrates, polyols, organic acids, and amino acids were extracted as described by Gravot and associates (2010). Briefly, extractions were performed using methanol containing BABA and ribitol as internal standards (for UPLC and GC analysis, respectively). Then, polar metabolites were purified from the extract through a phase partition procedure using methanol/chloroform/water (2:1:2). The polar phase was withdrawn and used for subsequent targeted profiling of soluble primary metabolites, according to Gravot and associates (2010). Amino acids were derivatized with AccQ-Tag (Waters, Milford, MA, U.S.A.), then analyzed using an Acquity UPLC-DAD system (Waters) according to Jubault and associates (2008). For nonstructural carbohydrates, polyols, and organic acids, analyses were performed using GC-flame ionization detection (FID) according to Lugan and associates (2009) and Adams and associates (1999), using $N$-methy- $N$-(trimethylsilyl)trifluoroacetamide as the silylation agent. Thirty-five metabolites were quantified using external standard calibration curves, making reference to the internal standard signal and the sample DW. The identity of each metabolite was confirmed by UPLC-MS/MS and GC-MS analysis (discussed below), based on the comparison of retention times and mass spectra with those of authentic compounds.

Two peaks from the UPLC chromatograms were initially unidentified, although their reactivity with the AccQ-Tag reagent suggested the presence of at least one amine group. Using mass spectra from UPLC-MS/MS analysis and comparison of retention times with authentic molecules, these two compounds were identified as being GSSG and SMC. Five additional peaks - three from UPLC chromatograms (noted X1 to X3) and two from GC-FID chromatograms (noted X4 and X5)were retained for analysis because they showed differential areas between inoculated and noninoculated samples. All information on mass spectra and the retention times of the Xn compounds, SMC and GSSG, are provided in Supplementary Table $\mathrm{S} 1$. No trace of reduced GSH was detected in sample extracts. Additional quantification of total GSH pool was performed on 100 to $150 \mathrm{mg}$ of fresh frozen material using dedicated extraction and analysis procedures according to Fahey and Newton (1987).

GC-MS analysis was performed according to Lugan and associates (2009). For UPLC-MS/MS analysis, a Waters Quattro Premier XE was used (Waters), equipped with an electrospray ionization source and coupled to an Acquity UPLC system (Waters). Chromatographic separation was achieved using an Acquity UPLC BEH $\mathrm{C}_{18}$ column (100 by $2.1 \mathrm{~mm}, 1.7 \mu \mathrm{m}$; Waters), coupled to an Acquity UPLC BEH $\mathrm{C}_{18}$ precolumn ( 2.1 by $5 \mathrm{~mm}, 1.7 \mu \mathrm{m}$; Waters). The mobile phase consisted of i) AccQTag eluent A (Waters) and ii) acetonitrile, using the same gradient as for amino acid quantification above, with a sample injection volume of $1 \mu \mathrm{l}$. Nitrogen generated from pressurized air in an N2G nitrogen generator (Mistral, Schmidlin-dbs-AG, Châtelaine, Switzerland) was used as the drying and nebulizing gas. The nebulizer gas flow was set to approximately 50 liters/h and the desolvatation gas flow to 900 liters/h. The interface temperature was set at $400^{\circ} \mathrm{C}$ and the source temperature at $135^{\circ} \mathrm{C}$. The capillary voltage was set at $3.4 \mathrm{kV}$ and the cone voltage at $25 \mathrm{~V}$; the ionization was in positive mode. Low-mass and high-mass resolution were 15 for both mass analyzers, ion energies 1 and 2 were $0.5 \mathrm{~V}$, entrance and exit potential were 2 and $1 \mathrm{~V}$, and detector (multiplier) gain was $650 \mathrm{~V}$. Data acquisition and analysis were performed with the MassLynx software v.4.1 (Waters). Absorbance was also monitored with a diode array at $260 \mathrm{~nm}$. Samples were analyzed in full-scan mode $(\mathrm{m} / \mathrm{z}=240$ to 700$)$.

Nitrate was extracted and quantified from $5 \mathrm{mg}$ of dry powder according to Lugan and associates (2009). Total nitrogen and sulfur contents were analyzed from $5 \mathrm{mg}$ and $800 \mu \mathrm{g}$ of dry matter, respectively, using the Dumas combustion method and a FlashEA 1112 N/Protein Analyzer (Thermo Scientific, San Jose, CA, U.S.A.) for $\mathrm{N}$ analysis, and a Flash EA 1112 CHNS/O Thermo Electron for $\mathrm{S}$ analysis (Thermo Scientific).

\section{In planta quantification of $P$. brassicae DNA.}

Total DNA was extracted from freeze-dried root samples using the DNeasy Animal Blood and Tissue Kit (Qiagen, Hilden, Germany), following the manufacturer's instructions. The DNA concentration was measured using a Nanodrop ND-1000 Spectrophotometer (Labtech, Palaiseau, France). For each time point, pathogen DNA was quantified using the primers $\mathrm{Pb} 4-1$ and PbITS6, designed to specifically amplify the internal transcribed spacer (ITS) region of $P$. brassicae (Sundelin et al. 2010). The results were normalized with the $B$. napus cruciferin A reference gene, amplified with the primers MDB510 
and MDB511 (Wu et al. 2010). Quantitative real-time polymerase chain reaction (PCR) was performed in a final volume of $12.5 \mu 1$, with 5 pmol of each primer, $6.25 \mu 1$ of $2 \times$ Light $C y-$ cler 480 SYBR GREEN I Master (Roche Diagnostics GmbH, Mannheim, Germany), and 5 ng of the target genomic DNA. PCR was performed in the Light Cycler 480 (Roche Diagnostics $\mathrm{GmbH}$ ). After initial denaturation at $95^{\circ} \mathrm{C}$ for $5 \mathrm{~min}$, target DNA was amplified for 50 cycles $\left(95^{\circ} \mathrm{C}\right.$ for $15 \mathrm{~s}, 58^{\circ} \mathrm{C}$ for $30 \mathrm{~s}$, and $72^{\circ} \mathrm{C}$ for $30 \mathrm{~s}$ ). Fluorescence was detected after each cycle. A final step at $95^{\circ} \mathrm{C}$ for $15 \mathrm{~s}$ and $58^{\circ} \mathrm{C}$ for $30 \mathrm{~s}$ was followed by the dissociation of the PCR products (temperature ramp of $0.11^{\circ} \mathrm{C} / \mathrm{s}$ ) until $95^{\circ} \mathrm{C}$ was reached, with a continuous fluorescence detection. To ensure data homogeneity, all the samples were analyzed in the same 384-well plate. The PCR reaction was set up in triplicate for each DNA sample and the experiment was repeated twice. Relative quantification was based on the methodology described by Pfaffl (2001). Amplification specificity was checked for each run by analyzing the melting curve of the PCR products.

\section{Histopathology experiments.}

Yudal roots were collected weekly from 14 to 35 dpi and fixed in $2 \%$ glutaraldehyde in phosphate buffer $(0.1 \mathrm{mM}, \mathrm{pH}$ 7.2) for 3 days at room temperature under vacuum. Samples were rinsed four times in phosphate buffer and once in water. Fixed samples were then dehydrated at room temperature with a graded series of ethanol $(10,30,50,70,90$, and $100 \%$ twice) for 10 min each. Samples were then embedded in Technovit 7100 resin (Heraeus Kulzer, Wehrheim, Germany) according to the manufacturer's recommendations. Sections ( $4 \mu \mathrm{m}$ thick) were cut with a semiautomatic rotary microtome (Microm Microtech, Francheville, France), and stained with $1 \%$ toluidine blue O (Sigma-Aldrich, St. Louis).

\section{Statistical analysis.}

Statistically relevant differences in the DI values of the 18 genotypes were analyzed using a generalized linear model implemented in the Statistical Analysis System (SAS) software package (v. 8.1, PROC GLM; SAS Institute Inc., Cary, NC, U.S.A.). A one-way analysis of variance (ANOVA) was followed by multiple mean comparisons using Student-NewmanKeuls tests $(\alpha=0.05)$. The model used was as follows: $Y_{i j}=m+$ $G_{i}+e_{i j}$, where $Y_{i j}$ is the DI of the genotype $i, G_{i}$ is the genotypic effect, and $e_{i j}$ is the residual. Nonparametric KruskalWallis one-way ANOVA was performed to compare the relative pathogen DNA contents between the Yudal samples using the same model as above, followed by multiple comparison Z-value tests using Statistica (v. 7.1; Statsoft, Tulsa, OK, U.S.A.).

Hierarchical clustering analyses of the 18 genotypes and the metabolites were performed with the software DARwin (v. 5.0; Perrier and Jacquemoud-Collet, CIRAD, Montpellier, France); dissimilarities were calculated using Manhattan distances and clustering was performed using Ward hierarchical clustering.

PCA were carried out on the whole set of inoculated and noninoculated plants in the 18-genotypes experiment, using the mean value of each combination analyzed (genotype-inoculation). Spearman correlation coefficients $(P<0.05)$ were calculated between the DI and the logarithmic ratios of the metabolic contents in inoculated and noninoculated plants. The metabolic levels in inoculated and noninoculated plants were compared using Mann-Whitney $U$ tests $(P<0.05)$. PCA, calculations of Spearman correlations coefficients, and MannWhitney $U$ tests were performed using Statistica.

Linear discriminant analyses were performed to separate the inoculated from the noninoculated genotypes within low-DI and high-DI groups, using the MASS package (Venables and
Ripley 2002) from R software (R Development Core Team, Vienna).

\section{ACKNOWLEDGMENTS}

We thank M. Chevalier (UMR GenHort, INRA Angers) for his helpful discussions in histopathology, D. Renault (UMR EcoBio, CNRS Rennes) for GC-MS analysis, O. Hénin (UMR Géosciences, CNRS Rennes) for nitrate quantifications, and the technical staff of UMR APBV for their assistance during this project. This project was financially supported by PROMOSOL and CETIOM. G. Wagner is a Ph.D. student funded by Région Bretagne and Direction Générale de l'Enseignement et de la Recherche. The study was conceived and designed by G. Wagner, A. Gravot, and M. J. Manzanares-Dauleux. G. Wagner obtained and analyzed the data. A. Laperche established the set of rapeseed genotypes. G. Wagner, S. Charton, C. Lariagon, J. Hopkins, and R. Lugan carried out quantification of metabolites and pathological tests. G. Wagner, A. Gravot, R. Delourme, A. Bouchereau, and M. J. Manzanares-Dauleux contributed to the interpretation of results. G. Wagner wrote the manuscript and A. Gravot, P. Frendo, R. Delourme, A. Bouchereau, A. Laperche, and M. J. ManzanaresDauleux proofread the manuscript. All authors read and approved the final manuscript.

\section{LITERATURE CITED}

Abbes, Z., Kharrat, M., Delavault, P., Chaïbi, W., and Simier, P. 2008. Nitrogen and carbon relationships between the parasitic weed Orobanche foetida and susceptible and tolerant faba bean lines. Plant Physiol. Biochem. 47:153-159.

Adams, M. A., Chen, Z. L., Landman P., and Colmer, T. D. 1999. Simultaneous determination by capillary gas chromatography of organic acids, sugars, and sugar alcohols in plant tissue extracts as their trimethylsilyl derivatives. Anal. Biochem. 266:77-84.

Agarwal, A., Kaul, V., Faggian, R., Rookes, J. E., Ludwig-Müller, J., and Cahill, D. M. 2011. Analysis of global host gene expression during the primary phase of the Arabidopsis thaliana-Plasmodiophora brassicae interaction. Funct. Plant Biol. 38:462-478.

Baldacci-Cresp F., Chang C., Maucourt M., Deborde C., Hopkins J., Lecomte P., Brouquisse R., Moing A., Abad P., Hérouart D., Puppo A. Favery B., and Frendo P. 2012. (Homo)glutathione deficiency impairs root-knot nematode development in Medicago truncatula. PloS Pathog. 8:e1002471.

Bashandy, T., Guilleminot, J., Vernoux, T., Caparros-Ruiz, D., Ljung, K., Meyer, Y., and Reichheld, J. P. 2010. Interplay between the NADPlinked thioredoxin and glutathione systems in Arabidopsis auxin signaling. Plant Cell 22:376-391.

Brodmann, D., Schuller, A., Ludwig-Müller, J., Aeschbacher, R. A., Wiemken, A., Boller, T., and Wingler, A. 2002. Induction of trehalase in Arabidopsis plants infected with the trehalose-producing pathogen Plasmodiophora brassicae. Mol. Plant-Microbe Interact. 15:693-700.

Buczacki, S. T., Toxopeus, H., Mattusch, P., Johnston, T. D., Dixon, G. R. and Hobolth, L. A. 1975. Study of physiological specialisation in Plasmodiophora brassicae: Proposals for attempted rationalization through an international approach. Trans. Br. Mycol. Soc. 65:295-303.

Cao, T., Srivastava, S., Rahman, M. H., Kav, N. N. V., Hotte, N., Deyholos, M. K., and Strelkov, S. E. 2008. Proteome-level changes in the roots of Brassica napus as a result of Plasmodiophora brassicae infection. Plant Sci. 174:97-115.

Deeken, R., Engelmann, J. C., Efetova, M., Czirjak, T., Muller, T., Kaiser, W. M., Tietz, O., Krischke, M., Mueller, M. J., Palme, K., Dandekar, T., and Hedrich, R. 2006. An integrated view of gene expression and solute profiles of Arabidopsis tumors: A genome-wide approach. Plant Cell 18:3617-3634

Del Carpio, D. P., Basnet, R. K., De Vos, R. C. H., Maliepaard, C., Visser, R., and Bonnema, G. 2011. The patterns of population differentiation in a Brassica rapa core collection. Theor. Appl. Genet. 122:1105-1118.

Depuydt, S., Trenkamp, S., Fernie, A. R., Elftieh, S., Renou, J. P., Vuylsteke, M., Holsters, M., and Vereecke, D. 2009. An integrated genomics approach to define niche establishment by Rhodococcus fascians. Plant Physiol. 149:1366-1386.

Devos, S., and Prinsen, E. 2006. Plant hormones: A key to clubroot development. Commun. Agric. Appl. Biol. Sci. 71:869-872.

Devos, S., Laukens, K., Deckers, P., Van der Straeten, D., Beeckman, T. Inze, D., Van Onckelen, H., Witters, E., and Prinsen, E. 2006. A hormone and proteome approach to picturing the initial metabolic events during Plasmodiophora brassicae infection on Arabidopsis. Mol. PlantMicrobe Interact. 19:1431-1443.

Duplessis, S., Cuomo, C. A., Lin, Y. C., Aerts, A., Tisserant, E., Veneault- 
Fourrey, C., Joly, D. L., Hacquard, S., Amselem, J., Cantarel, B. L., Chiu, R., Coutinho, P. M., Feau, N., Field, M., Frey, P., Gelhaye, E., Goldberg, J., Grabherr, M. G., Kodira, C. D., Kohler, A., Kues, U., Lindquist, E. A., Lucas, S. M., Mago, R., Mauceli, E., Morin, E., Murat, C., Pangilinan, J. L., Park, R., Pearson, M., Quesneville, H., Rouhier, N., Sakthikumar, S., Salamov, A. A., Schmutz, J., Selles, B., Shapiro, H., Tanguay, P., Tuskan, G. A., Henrissat, B., Van de Peer, Y., Rouze, P., Ellis, J. G., Dodds, P. N., Schein, J. E., Zhong, S. B., Hamelin, R. C., Grigoriev, I. V., Szabo, L. J., and Martin, F. 2011. Obligate biotrophy features unraveled by the genomic analysis of rust fungi. Proc. Natl. Acad. Sci. U.S.A. 108:9166-9171.

Evans, J., and Scholes, J. D. 1995. How does clubroot alter the regulation of carbohydrate metabolism in its host? Asp. Appl. Biol. 42:125-132.

Fahey, R. C., and Newton, G. L. 1987. Determination of low-molecular weight thiols using monobromobimane fluorescent labeling and high performance liquid chromatography. Pages 85-96 in: Methods in Enzymology. W. B. Jakoby and O. W. Griffith, eds. Academic Press, San Diego, CA, U.S.A

Fähling, M., Graf, H., and Siemens, J. 2003. Pathotype separation of Plasmodiophora brassicae by the host plant. J. Phytopathol. 151:425-430.

Frendo, P., Harrison, J., Norman, C., Jimenez, M. J. H., Van de Sype, G., Gilabert, A., and Puppo, A. 2005. Glutathione and homoglutathione play a critical role in the nodulation process of Medicago truncatula. Mol. Plant-Microbe Interact. 18:254-259.

Frisvad, J. C., Andersen, B., and Thrane, U. 2008. The use of secondary metabolite profiling in chemotaxonomy of filamentous fungi. Mycol. Res. 112:231-240.

Giovanelli, J., Mudd, S. H., and Datko, A. H. 1980. Sulfur amino acids in plants. Pages 453-487 in: The Biochemistry of Plants, Volume 5. B. J. Miflin, ed. Academic Press, New York.

Gravot, A., Dittami, S. M., Rousvoal, S., Lugan, R., Eggert, A., Collen, J., Boyen, C., Bouchereau, A., and Tonon, T. 2010. Diurnal oscillations of metabolite abundances and gene analysis provide new insights into central metabolic processes of the brown alga Ectocarpus siliculosus. New Phytol. 188:98-110.

Gravot, A., Grillet, L., Wagner, G., Jubault, M., Lariagon, C., Baron, C., Deleu, C., Delourme, R., Bouchereau, A., and Manzanares-Dauleux, M. J. 2011. Genetic and physiological analysis of the relationship between partial resistance to clubroot and tolerance to trehalose in Arabidopsis thaliana. New Phytol. 191:1083-1094.

Hofmann, J., Szakasits, A. B., Sobczak, M., Daxböck-Horvath, S., Golinowski, W., Bohlmann, H., and Grundler, F. 2008. Starch serves as carbohydrate storage in nematode-induced syncytia. Plant Physiol. $146: 228-235$

Hofmann, J., El Ashry, A., Anwar, S., Erban, A., Kopka, J., and Grundler, F. 2010. Metabolic profiling reveals local and systemic responses of host plants to nematode parasitism. Plant J. 62:1058-1071.

Jacob, C., Anwar, A., and Burkholz, T. 2008. Perspective on recent developments on sulfur-containing agents and hydrogen sulfide signaling. Planta Med. 74:1580-1592.

Jones, M. G., Hughes, J., Tregova, A., Milne, J., Tomsett, A. B., and Collin, H. A. 2004. Biosynthesis of the flavour precursors of onion and garlic. J. Exp. Bot. 55:1903-1918.

Jubault, M., Hamon, C., Gravot, A., Lariagon, C., Delourme, R., Bouchereau, A., and Manzanares-Dauleux, M. J. 2008. Differential regulation of root arginine catabolism and polyamine metabolism in clubroot-susceptible and partially resistant Arabidopsis genotypes. Plant Physiol. 46:2008-2019.

Kageyama, K., and Asano, T. 2009. Life cycle of Plasmodiophora brassicae. J. Plant Growth Regul. 28:203-211.

Keen, N. T., and Williams P. H. 1969a. Synthesis and degradation of starch and lipids following infection of cabbage by Plasmodiophora brassicae. Phytopathology 59:778-785.

Keen, N. T., and Williams, P. H. 1969b. Translocation of sugars into infected cabbage tissues during clubroot development. Plant Physiol. 44:748-754

Kemen, E., Gardiner, A., Schultz-Larsen, T., Kemen, A. C., Balmuth, A. L., Robert-Seilaniantz, A., Bailey, K., Holub, E., Studholme, D. J., MacLean, D., and Jones, J. D. G. 2011. Gene gain and loss during evolution of obligate parasitism in the white rust pathogen of Arabidopsis thaliana. PLoS Biol. 9:e1001094

Kiers, E. T., Duhamel, M., Beesetty, Y., Mensah, J. A., Franken, O., Verbruggen, E., Fellbaum, C. R., Kowalchuk, G. A., Hart, M. M., Bago, A., Palmer, T. M., West, S. A., Vandenkoornhuyse, P., Jansa, J., and Bücking, H. 2011. Reciprocal rewards stabilize cooperation in the mycorrhizal symbiosis. Science 333:880-882.

Koprivova, A., Mugford, S. T., and Kopriva, S. 2010. Arabidopsis root growth dependence on glutathione is linked to auxin transport. Plant Cell Rep. 29:1157-1167.

Ludwig-Müller, J., Prinsen, E., Rolfe, S. E., and Scholes, J. D. 2009. Me- tabolism and plant hormone action during clubroot disease. J. Plant Growth Regul. 28:229-244.

Lugan, R., Niogret, M. F., Kervazo, L., Larher, F. R., Kopka, J., and Bouchereau, A. 2009. Metabolome and water status phenotyping of Arabidopsis under abiotic stress cues reveals new insight into ESK1 function. Plant Cell Environ. 32:95-108.

Manzanares-Dauleux, M. J., Delourme, R., Baron, F., and Thomas, G. 2000a. Mapping of one major gene and of QTLs involved in resistance to clubroot in Brassica napus. Theor. Appl. Genet. 101:885-891.

Manzanares-Dauleux, M. J., Delourme, R., Glory, P., and Thomas, G. 2000b. Isolate-specific resistance to clubroot in Brassica napus is expressed at high or partial level. Cruciferae Newsl. 22:57-58.

Manzanares-Dauleux, M. J., Divaret, I., Baron, F., and Thomas, G. 2001. Assessment of biological and molecular variability between and within field isolates of Plasmodiophora brassicae. Plant Pathol. 50:165-173.

Manzanares-Dauleux, M. J., Delourme, R., Glory, P., Giboulot, A., and Thomas, G. 2003. Mapping QTLs and major resistance genes to clubroot (Plasmodiophora brassicae) in Brassica napus. Pages 105-107 in: Proceedings of the 11th International Rapeseed Congress, Copenhagen, Denmark.

Mattusch, P. 1977. Epidemiology of clubroot of crucifers caused by Plasmodiophora brassicae. Pages 24-28a in: Woronin + 100 International Conference on Clubroot. S. T. Buczacki and P. H. Williams, eds. Madison, WI, U.S.A.

Mitchell, D. T., and Rice, K. A. 1979. Translocation of ${ }^{14} \mathrm{C}$-labelled assimilates in cabbage during clubroot development. Ann. Appl. Biol. 92:143152.

Mithen, R., and Magrath, R. 1992. A contribution to the life history of Plasmodiophora brassicae: secondary plasmodia development in root galls of Arabidopsis thaliana. Mycol. Res. 96:877-885.

Noctor, G., and Foyer, C. H. 1998. Ascorbate and glutathione: keeping active oxygen under control. Annu. Rev. Plant Physiol. Plant Mol. Biol. 49:249-279.

Noctor, G., Mhamdi, A., Chaouch, S., Han, Y., Neukermans, J., MarquezGarcia, B., Queval, G., and Foyer, C. H. 2011. Glutathione in plants: an integrated overview. Plant Cell Environ. 35:454-484.

Pate, J. S., Rasins, E., Thumfort, P. P., McChesney, C. J., and Meney, K. A. 1995. Occurrence of the unusual amino compound S-methyl cysteine in Australian members of the Restionaceae-biological and taxonomic significance. Aust. J. Bot. 43:73-84.

Paul, M. J., Primavesi, L. F., Jhurreea, D., and Zhang, Y. 2008. Trehalose metabolism and signaling. Annu. Rev. Plant Biol. 59:417-441.

Paul, N. K., Johnston, T. D., and Eagles, C. F. 1986. Inheritance of S-methylL-cysteine sulphoxide and thiocyanate contents in forage rape (Brassica napus L.). Theor. Appl. Genet. 72:706-709.

Pfaffl, M. W. 2001. A new mathematical model for relative quantification in real-time RT-PCR. Nucleic Acids Res. 29:2002-2007.

Rébeillé, F., Jabrin, S., Bligny, R., Loizeau, K., Gambonnet, B., Van Wilder, V., Douce, R., and Ravanel, S. 2006. Methionine catabolism in Arabidopsis cells is initiated by a gamma-cleavage process and leads to $S$-methylcysteine and isoleucine syntheses. Proc. Natl. Acad. Sci. U.S.A. 103:15687-15692.

Schuller, A., and Ludwig-Müller, J. 2006. A family of auxin conjugate hydrolases from Brassica rapa: characterization and expression during clubroot disease. New Phytol. 171:145-158.

Siemens, J., Keller, I., Sarx, J., Kunz, S., Schuller, A., Nagel, W., Schmulling, T., Parniske, M., and Ludwig-Müller, J. 2006. Transcriptome analysis of Arabidopsis clubroots indicate a key role for cytokinins in disease development. Mol. Plant-Microbe Interact. 19:480-494.

Siemens, J., Gonzalez, M. C., Wolf, S., Hofmann, C., Greiner, S., Du, Y. J., Rausch, T., Roitsch, T., and Ludwig-Müller, J. 2011. Extracellular invertase is involved in the regulation of clubroot disease in Arabidopsis thaliana. Mol. Plant Pathol. 12:247-262.

Simoh, S., Quintana, N., Kim, H. K., Choi, Y. H., and Verpoorte, R. 2009. Metabolic changes in Agrobacterium tumefaciens-infected Brassica rapa. J. Plant Physiol. 166:1005-1014.

Snoeijers, S. S., Perez-Garcia, A., Joosten, M., and De Wit, P. 2000. The effect of nitrogen on disease development and gene expression in bacterial and fungal plant pathogens. Eur. J. Plant Pathol. 106:493-506.

Somé, A., Manzanares, M. J., Laurens, F., Baron, F., Thomas, G., and Rouxel, F. 1996. Variation for virulence on Brassica napus L. amongst Plasmodiophora brassicae collections from France and derived singlespore isolates. Plant Pathol. 45:432-439.

Steinfath, M., Strehmel, N., Peters, R., Schauer, N., Groth, D., Hummel, J., Steup, M., Selbig, J., Kopka, J., Geigenberger, P., and van Dongen, J. T. 2010. Discovering plant metabolic biomarkers for phenotype prediction using an untargeted approach. Plant Biotechnol. J. 8:900911.

Sundelin, T., Christensen, C. B., Larsen, J., Moller, K., Lubeck, M., Bodker, L., and Jensen, B. 2010. In planta quantification of Plasmodiophora 
brassicae using signature fatty acids and real-time PCR. Plant Dis. 94:432-438

Vanacker, H., Foyer, C. H., and Carver, T. L. W. 1999. Changes in apoplastic antioxidants induced by powdery mildew attack in oat genotypes with race non-specific resistance. Planta 208:444-452.

Vanacker, H., Carver, T. L. W., and Foyer, C. H. 2000. Early $\mathrm{H}_{2} \mathrm{O}_{2}$ accumulation in mesophyll cells leads to induction of glutathione during the hyper-sensitive response in the barley-powdery mildew interaction. Plant Physiol. 123:1289-1300.

Venables, W. N., and Ripley, B. D. 2002. Modern Applied Statistics with S, Fourth Edition. Springer, New York.

Vivancos, P. D., Dong, Y. P., Ziegler, K., Markovic, J., Pallardo, F. V., Pellny, T. K., Verrier, P. J., and Foyer, C. H. 2010. Recruitment of glutathione into the nucleus during cell proliferation adjusts whole-cell redox homeostasis in Arabidopsis thaliana and lowers the oxidative defence shield. Plant J. 64:825-838.
Williams, P. H., Keen, N. T., Strandberg, J. O., and McNabola, S. S. 1968. Metabolic synthesis and degradation during clubroot development in cabbage hypocotyls. Phytopathology 58:921-928.

Wingler, A., Fritzius, T., Wiemken, A., Boller, T., and Aeschbacher, R. A. 2000. Trehalose induces the ADP-glucose pyrophosphorylase gene, ApL3, and starch synthesis in Arabidopsis. Plant Physiol. 124:105114.

Wu, G., Zhang, L., Wu, Y. H., Cao, Y. L., and Lu, C. M. 2010. Comparison of five endogenous reference genes for specific PCR detection and quantification of Brassica napus. J. Agric. Food Chem 58:2812-2817.

Zurbriggen, M. D., Carillo, N., Tognetii, V.B., Melzer, M., Martin, P., Hause, B., and Hajirezaei, M. R. 2009. Chloroplast-generated reactive oxygen species play a major role in localized cell death during the nonhost interaction between tobacco and Xanthomonas campestris pv. vesicatoria. Plant J. 60:962-973. 